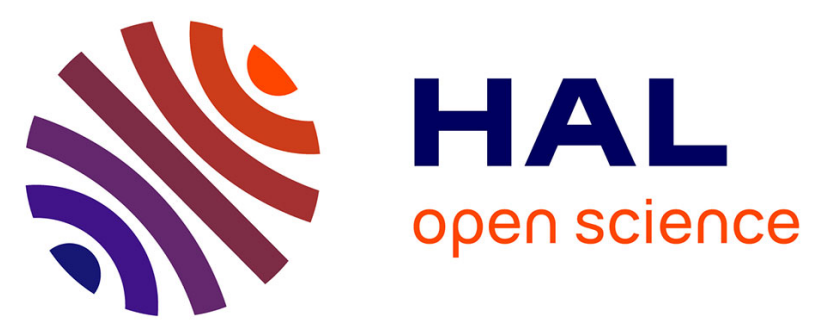

\title{
Support for Life Cycle Decision-Making in Sustainable Manufacturing - Results of an Industrial Case Study
}

Teuvo Uusitalo, Jyri Hanski, Markku Reunanen, Susanna Kunttu

\section{To cite this version:}

Teuvo Uusitalo, Jyri Hanski, Markku Reunanen, Susanna Kunttu. Support for Life Cycle DecisionMaking in Sustainable Manufacturing - Results of an Industrial Case Study. IFIP International Conference on Advances in Production Management Systems (APMS), Sep 2014, Ajaccio, France. pp.162-169, 10.1007/978-3-662-44736-9_20 . hal-01387861

\section{HAL Id: hal-01387861 \\ https://inria.hal.science/hal-01387861}

Submitted on 26 Oct 2016

HAL is a multi-disciplinary open access archive for the deposit and dissemination of scientific research documents, whether they are published or not. The documents may come from teaching and research institutions in France or abroad, or from public or private research centers.
L'archive ouverte pluridisciplinaire HAL, est destinée au dépôt et à la diffusion de documents scientifiques de niveau recherche, publiés ou non, émanant des établissements d'enseignement et de recherche français ou étrangers, des laboratoires publics ou privés. 


\title{
Support for life cycle decision-making in sustainable manufacturing - results of an industrial case study
}

\author{
Teuvo Uusitalo, Jyri Hanski, Markku Reunanen, Susanna Kunttu \\ VTT TECHNICAL RESEARCH CENTRE OF FINLAND \\ Tekniikankatu 1, P.O. Box 1300, FIN-33101 Tampere, Finland \\ \{teuvo.uusitalo, jyri.hanski, markku.reunanen, \\ susanna.kunttu\} @vtt.fi
}

\begin{abstract}
This paper presents results of a case study in which a life cycle cost estimation tool has been developed and tested. Improving sustainability requires holistic information on the life cycle costs of the system. There is a need to increase the transparency of decision-making by informing customers about the costs of the solutions when taking into consideration the whole life cycle. This benefits both the supplier and the customer in forms of showing the total costs of the system and selecting the system with the lowest total costs.
\end{abstract}

Keywords: sustainability, manufacturing, life cycle cost, case study

\section{Introduction}

Sustainability and the analysis of life cycle costs have received considerable attention in the manufacturing industry lately. Procurement and supply chain are in central position in achieving sustainability and are increasingly being demanded to contribute to goals of sustainable development $[1,2,3]$. Supply chain management studies have emphasised the benefits of sustainability in the form of risk reduction and performance enhancement $[4,5]$. It is generally believed that assessing the sustainability of the system requires holistic information on the life cycle costs of the system. However, according to the interviews made for this study, the use of life cycle cost as a procurement criterion instead of just the acquisition price is still not a predominant practice among procurers. The main reason for using acquisition price as a main criterion is usually rooted in the preferences of the procurement department.

Miemczyk et al. [1] lists social, environmental and economic measures found in a literature review on sustainable procurement and supply management. The following list includes some of the economic and environmental measures: generic internal processes such as supplier selection and assessment (material, waste, recycling); cost of implementing sustainability practices; inclusion of sustainability criteria in design of products; measurement and control of energy use and greenhouse gas emissions; life cycle analysis principles (LCA); developing activities at procurement strategy level to support sustainability; and developing sustainable products together with suppliers.

adfa, p. 1, 2011.

(C) Springer-Verlag Berlin Heidelberg 2011 
Procurement decisions are an important application area for life cycle cost related decision-making. A product system's life cycle is characterized by three phases: beginning of life (BOL), including design and production, middle-of-life (MOL), including use, service and maintenance and end-of-life (EOL), characterized by various scenarios such as reuse of the product and components, refurbishing, material reclamation and, finally, disposal [6].

Dowlatshahi argues that most of the total life cycle cost of a product is committed during the design stage [7]. The total costs can be reduced by giving due consideration to life cycle cost issues early in the design. LCC analysis provides the framework for specifying the estimated total incremental costs of the development, production, usage and retirement of a particular item. [8] Tools should be developed to allow a precise estimation of the whole life cycle impact and costs of a product. These tools should be used during the design process to gather information from the real history of existing products. [9]

An important step in LCC analysis is the classification of the analysis objectives and the bounding of the problem so that it can be studied efficiently and in a timely manner. LCC analysis can be used, for instance, in the following decision-making situations [8]:

- decisions on system maintenance concepts and logistics support policies

- decisions on equipment design configuration

- decisions on procurement sources and the selection of a supplier for a given item

- decisions on maintenance plans

- decisions on product disposal and recycling methods

The gap for this study was identified as follows: there is a need to develop a tool for explaining life cycle costs of solutions. Such tools do not currently exist at least according to the interviewees made for this study. Also, there is a need to increase the transparency of decision-making by informing customers about the costs of the solutions when taking into consideration the whole life cycle. This benefits both the supplier and the customer in forms of showing the total costs of the system and selecting the system with the lowest total costs. Typically, purchasing price is only a small fraction of the whole life cycle costs. In addition, reported cases of testing such a tool are scarce. Thereby, the objectives of this study are:

- To describe a decision support tool for a solution provider and the need for such a tool

- To test the tool with customers

- To identify further development needs for the tool

\section{Methodology}

The research method applied was a qualitative case study. The research data were collected in workshops with the case company and through structured interviews with the case company's customers. The case-specific LCC prototype tool was first developed in close co-operation with the case company. The LCC tool was then tested with 
key customers of the case company. Testing approach is described in detail in chapter 4.1.

The case company is a small company providing power supply systems to the energy, ICT, transport and process industries. Case company's main focus is on solutions for energy producers and industrial plants. Its battery back-up systems are necessary for guaranteeing the 24/7 operation of critical devices also at any failure situations of the electrical mains network. Case company's products are typically customized solutions for its B-to-B customers, who are project suppliers of larger systems and integrate the solutions delivered by the case company to their own offerings to end-users.

The developed tool is a prototype and its main objective is to demonstrate how LCC calculations can be done and used in practise. The development of the tool has been an iterative process conducted in close co-operation between the case company and researchers. Researchers who were responsible for the development of the tool made the first version of the tool according to the requirement specifications defined at the outset of the development work. Then, during the development process feedback meetings were held on a regular basis between case company personnel and researchers.

\section{$3 \quad$ LCC tool description}

Figure 1 outlines the development processes of a company as part of the life cycle for $\mathrm{B}$ to $\mathrm{B}$ products that are typically delivered by establishing a delivery project with the customer. A company that follows this model develops a product portfolio at its own expense and then establishes projects with clients to sell and deliver products that are based on the elements of their product portfolio and are configured and designed to meet needs of the particular customer. LCC tool was originally meant to be utilised in delivery project negotiations with potential customers (External use of LCC calculations in Figure 1) to serve the case company's need to explain higher purchasing price with lower life cycle costs and more sustainable solutions. During the LCC tool development and testing the case company also used the tool to analyse the elements of their product portfolio which elicited new ideas to improve the product from the life cycle perspective (Internal use of LCC calculations in Figure 1).

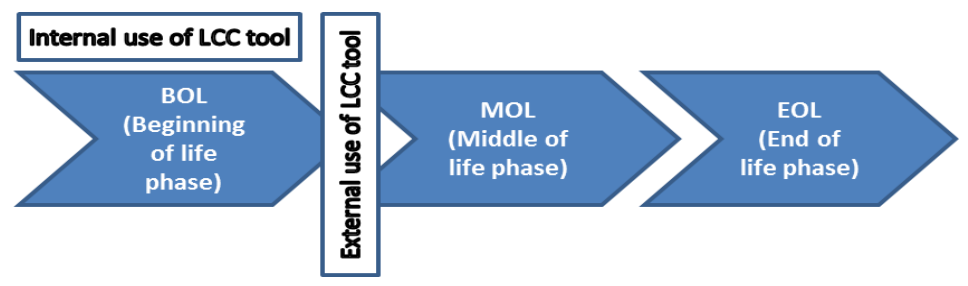

Fig. 1. Life cycle cost calculations can be utilised internally in the company or externally with customers. 
The use of the LCC tool can be described as a process with following steps:

1. Define the possible solutions that meet the customer's technical requirements and that are options to be analysed.

2. Populate the LCC tool with input data, i.e. give numerical values to the relevant cost parameters for current case. These include preventive maintenance (e.g. cost of person hours/task), corrective maintenance (e.g. MTBF, cost of unavailability), unavailability (e.g. cost/time unit), and disposal (e.g. cost of system disposal)

3. Calculate point estimates of life cycle costs. This is done automatically by the LCC tool.

4. Assess the uncertainty of numerical values of cost parameters given in the step 2 . Uncertainty is expressed by statistical distributions defined by a graphical tool implemented in the LCC tool.

5. Calculate expected variation of life cycle costs based on statistical distribution given in the step 4 . This is done automatically by the LCC tool.

6. Assess the results and compare the options using result indicators from the LCC calculation.

7. Make the decision for the current case based on economic criteria. For multivariate analysis other criteria can be used to support the decision.

MS Excel was chosen as the technical platform for the LCC tool as MS Excel is widely used in companies. The LCC tool is described in greater detail in [10].

\section{$4 \quad$ Results of LCC tool testing}

\subsection{Testing approach}

The LCC tool testing had two goals. The first goal is to test the tool from a technical point of view to ensure that the created software works correctly. The second, and in this case a more important, goal is to test the usefulness and usability of the LCC tool; i.e. the potential of the LCC tool to support purchase decisions of the customers.

Technical software testing has been done by researchers and case company personnel. The developed tool is a prototype and its main objective is to demonstrate how LCC calculations can be done and used in practise. Thus comprehensive software tests have not been conducted. Technical software tests have been done only to ensure that the tool works properly if user acts as expected. No systematic checks for e.g. wrong input data have been done. In practise technical software testing has been done in conjunction with internal testing at the case company by documenting any identified unexpected behaviour of the tool.

In order to get feedback from the usefulness and usability of the LCC tool in external use, tests were organized with case company's customers. In all, ten persons from seven different companies participated in the test sessions. The first test session was held with three representatives of company 1 . General feedback from the conducted test session was positive and the idea of focusing more on life cycle cost than mere acquisition cost was welcomed. The tool was seen a promising way to support life cycle cost based decision-making. The test session, however, failed in the sense that 
the test persons felt unable to give answers to most of the detailed questions concerning the usefulness and usability of the tool. The tool was demonstrated to the test persons by explaining the basic functionalities of the tool and by showing what kind of results will be received when the tool is populated with input data. The conducted test session revealed the importance of a well-designed test case that would be understood by the test persons.

The subsequent test sessions with test persons from companies 2 - 7 were supported by a test case description of four case company product options each provided with a representative input data set. The selected case system was a $110 \mathrm{~kW}$ power supply system which is typically used in power stations. The options to be compared by using the LCC tool were labelled as follows:

1. S1 - Modular solution

2. S2 - Modular solution + solar panels

3. S3 - Modular solution, no-good quality battery type

4. S4 - Conventional solution

Figure 2 presents a summary of the comparison of the test case options. The summary was made available to the test persons by the LCC tool.
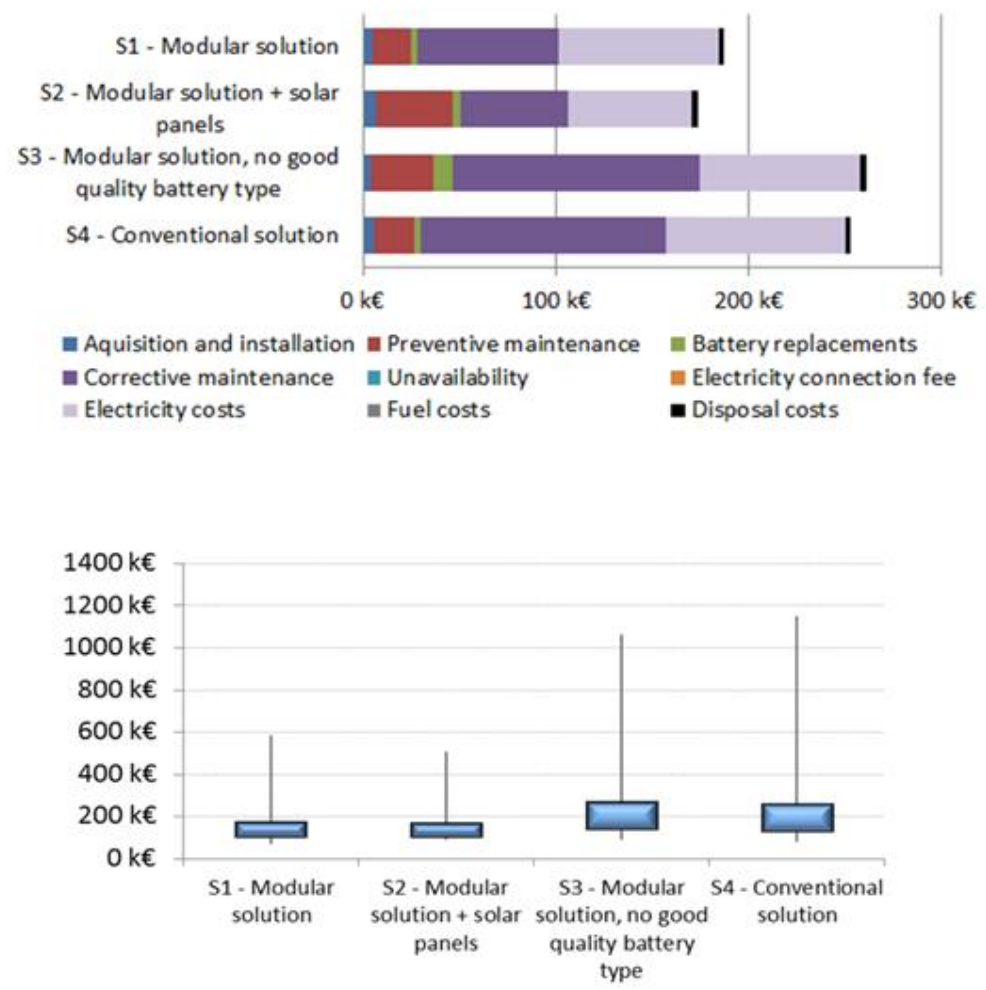

Fig. 2. Summary of the comparison of the test case options (Source: Panarese et al. (2014), p. 
In each test session the same improved test case was used to demonstrate the use of the LCC tool to the test persons from companies 2 - 7. After the demonstration the same set of questions that concerned the usefulness and usability of the LCC tool was asked from the test persons to generate deeper understanding on the potential of the LCC tool to support purchase decisions. This improved way of demonstrating the LCC tool to test persons seemed to greatly improve the ability and willingness of the test persons to answer the questions.

\subsection{Results of the testing}

Regarding the usefulness of the LCC tool the test persons were asked to give their overall assessment on a scale $1-5$. The average score was 4 individual points ranging from 3,25 to 5. The test persons seemed to appreciate case company's efforts to develop a tool that would support open discussions on sustainability and life cycle costs between suppliers and customers. None of the test persons had seen a corresponding tool being used by other companies for the same purpose even though life cycle cost often appears as an important aspect in marketing material. The test persons were of the opinion that the ability of a supplier to make life cycle cost information available to the customer can positively influence on who will be chosen as a supplier. The tool was felt especially useful when used in cooperation between supplier and customer.

One of the answers to a question whether the results that can be achieved by using the tool are worthwhile the effort needed was that potential savings from the use of the tool would often justify several days to be used for the LCC studies. Three test persons pointed out that selling and consulting customers always take time and tools that support these efforts are welcomed. One of the test persons pointed out the availability of input data and efforts that would facilitate data retrieval.

Regarding the usability of the LCC tool the test persons were asked to give their overall assessment on a scale $1-5$. The average score was 4,25 individual points ranging from 3,75 to 5 . Answers to the question whether the key performance indicators of the LCC tool are relevant, and whether the results are clearly presented to the user of the tool were positive with one exception. One of the test persons felt that he would need more experience on the use of the tool in order to be able to answer the question. Lack of experience also seemed to hamper the ability of the test persons to answer the questions that concerned the reliability of the results of the tool. Specific questions dealt with the availability of reliable input data and whether all relevant cost factors were included in the cost structure of the tool. One of the test persons was of the opinion that it is easy to find input data that is reliable enough. One of the test persons pointed out that the main purpose of this kind of a tool is to be indicative of major differences between the compared options. One of the test persons in turn pointed out that it is easy to update the comparisons when improved data becomes available. The rest of the test persons felt it hard to express their opinion due to lack of experience.

One of the usability questions concerned the number of options that can be compared by the LCC tool during one session. The current number of options is five and it was considered sufficient by all test persons. One of the test persons, however, noted 
that he had experience on acquisition projects where the number of options to be compared had been higher. This challenge can be overcome by the current version of the LCC tool by running a new session to compare another $2-5$ options.

As a final question regarding the usability of the tool the test persons were asked whether the tool is simple enough and easy to use and whether the test persons would be interested in using the tool by themselves. All test persons gave a positive answer to these questions.

\section{Conclusions}

The test results indicate that the LCC tool is useful especially when used in cooperation between the supplier and a customer. The developed LCC tool provides information to allow estimation of the life cycle impact and costs of a product. This supports decision making related to equipment design configuration, procurement sources, selection of suppliers, maintenance plans and product disposal.

So far the LCC tool has been in test phase and exploited in the preparation of a few offers only. Yet there is no proof of that case company would already have received new orders or new customers by applying the new tool. Case company sees that main benefits of the tool will be achieved in the future when the tool will be fully exploited in the negotiations with customers and in the development of own product portfolio.

The LCC tool still needs development before all benefits from the tool are achievable. Future development possibilities include a web service based on the developed tool combined with a database. With a web service company's customers can make their own calculations and comparisons which can be a competitive advantage for the company because their competitors currently fail to provide corresponding services. Adding a database behind the tool reduces the time needed for data input and enables other than case company experts use the tool. In addition social impacts of the solutions could be included in the tool so that all aspects of sustainability are taken into account.

Acknowledgements: The research leading to these results has received funding from the European Community's Seventh Framework Programme (FP7, 2007-2013) under grant agreement 262931 and Tekes - the Finnish Funding Agency for Innovation. The authors wish to acknowledge the European Commission and Tekes for their support.

\section{References}

1. Miemczyk, J., Johnsen, T.E., Macquet, M.: Sustainable purchasing and supply management: a structured literature review of definitions and measures at the dyad, chain and network levels. Supply Chain Management: An International Journal. vol. 17, no. 5, pp. 478-496 (2012)

2. Meehan, J., Bryde, D.: Sustainable procurement practice. Business Strategy and the Environment. vol. 20, no. 2, pp. 94-106 (2011) 
3. Srivastava, S.K.: Green supply-chain management: a state-of-the-art literature review. Int. J. of Management Reviews, Vol. 9 No. 1, pp. 53-80 (2007)

4. Jayaraman, V., Klassen, R., Linton, J.D.: Supply chain management in a sustainable environment. J. of Operations Management. Vol. 25 No. 6, pp. 1071-4 (2007)

5. Zhu, Q., Sarkis, J.: Relationships between operational practices and performance among early adopters of green supply chain management practices in Chinese manufacturing enterprises. J. of Operations Management. Vol. 22 No. 3, pp. 265-289 (2004)

6. Kiritsis, D., Nguyen, V.K., Stark, J.: How closed-loop PLM can improve knowledge management over the complete product lifecycle? Int. J. of Product Lifecycle Management. Vol. 3 No. 1, pp 54-77. (2008)

7. Dowlatshahi, S.: Product design in a concurrent engineering environment: an optimization approach. J. of Production Research. Vol. 30, No. 8, pp. 18031818 (1992)

8. Asiedu, Y., Gu, P.: Product life cycle cost analysis: State of the art review. Int. J. of Production Research. Vol. 36, pp. 883-908 (1998)

9. Garetti, M., Taisch, M: Sustainable manufacturing: trends and research challenges. Production Planning \& Control. Vol. 23 No. 2-3, pp. 83-104 (2012)

10. Panarese, D., Schaeperkoetter, C., Raukola, J., Reunanen, M., Macchi, M., Sergent, N.: Demonstration of SustainValue outputs in different environments. SustainValue deliverable D5.3. Available; http://www.sustainvalue.eu/publications/D5_3_Final.pdf [09 Apr 2014] (2014) 